\title{
PENGEMBANGAN APLIKASI GAME KISAH PANJI SAKTI BERBASIS MOBILE
}

\author{
Nyoman Trisna Adi Darma ${ }^{1}$, I Ketut Resika Arthana ${ }^{2}$, I Made Putrama ${ }^{3}$ \\ 1,2,3 Pendidikan Teknik Informatika, Universitas Pendidikan Ganesha \\ Singaraja, Indonesia
}

e-mail: trisnaadidarma@gmail.com ${ }^{1}$, resika@undiksha.ac.id², made.putrama@undiksha.ac.id ${ }^{3}$

\begin{abstract}
Abstrak
Tujuan dari penelitian ini adalah: (1) mendesain dan mengimplementasikan Panji Sakti Story Game Based Mobile. (2) Untuk mengetahui tanggapan pengguna terhadap Panji Sakti Story Game Based Mobile.

Metode yang digunakan dalam penelitian ini adalah penelitian dan pengembangan. Panji Sakti Story Game Based Mobile ini dikembangkan dengan menggunakan Model ADDIE. Subyek penelitian ini adalah generasi muda dengan rentang usia 16 sampai 30 dengan menggunakan kuesioner. Data yang diperoleh dianalisis secara deskriptif.

Hasil penelitian ini adalah aplikasi yang diimplementasikan dengan menggunakan bahasa pemrograman C\# dengan Unity Editor. Semua fitur yang ada dalam Panji Sakti Story Game Based Mobile berjalan dengan baik. Tanggapan pengguna terhadap Panji Sakti Story Game Based Mobile termasuk dalam rentang yang sangat baik.
\end{abstract}

\begin{abstract}
He aims of this study are: (1) to design and to implement Panji Sakti Story Game Based Mobile. (2) To know the users' response to Panji Sakti Story Game Based Mobile.

The methods that were used in this study were research and development. This Panji Sakti Story Game Based Mobile was developed using ADDIE Model. The subjects of this study were the young generations with an age range of 16 to 30 by using questionnaire. The obtained data were analyzed descriptively.

The results of this study are the application is implemented using C\# programming language with Unity Editor. All of features contained in Panji Sakti Story Game Based Mobile went well. The users's responses to Panji Sakti Story Game Based Mobile belong in a very good range.
\end{abstract}

Keywords : Game Adventure, ADDIE, Panji Sakti Story, Unity, Mobile

\section{PENDAHULUAN}

Indonesia memiliki 34 provinsi, dan 514 kabupaten. Dilihat dari banyaknya daerah yang dimilikinya membuat Indonesia kaya akan budaya, cerita rakyat, dan sejarah. Cerita rakyat merupakan cerita yang berkembang dikalangan rakyat dari jaman dulu hingga saat ini yang turunmenurun kesetiap generasinya.

Di Bali sangat banyak dan beragam cerita rakyat yang ada dan terus diceritakan rakyatnya turun temurun ke generasi berikutnya. Kabupaten Buleleng khususnya, terdapat cerita tentang Ki Barak Panji atau yang lebih familiar didengar dengan Panji Sakti. Dalam cerita tersebut banyak mengandung pesan moral yang berkaitan tentang kehidupan yang baik dijadikan panutan.

Panji Sakti sakti merupakan anak dari seorang raja Sri Aji Dalem Sagening dengan abdi raja yang bernama Si Luh Pasek Panji. Raja Sri Aji Dalem Sagening memiliki patih yang sangat setia, dari leluhurnya dulu hingga saat ini, masih setia mengabdi dengan raja. Patih itu bernama Arya Jarantik, beliau lah yang diberikan mandat untuk mengangkat Panji Sakti 
sebagai anak angkatnya dan menjaganya bersama Ibu Panji Sakti.

Sejak lahir Panji Sakti sudah memiliki kelebihan, terdapat sinar yang memancar dari ubun-ubunnya, beliau tampan tanpa cacat sedikitpun. Setelah Panji Sakti dewasa beliau diperintahkan untuk pulang ke daerah ibunya di Desa Panji, Den Bukit oleh raja, dari sana lah pertualangan dimulai.

Tetapi dewasa ini masyarakat masih banyak yang belum mengetahui cerita rakyat Panji Sakti, terutama pada generasi muda pada rentangan umur 16 - 30 tahun. Dari hasil survei yang penulis lakukan, $44.8 \%$ pemuda menjawab tidak pernah dengar, $55,2 \%$ menjawab pernah mendengar, hasil survei lebih detail akan dilampirkan.

Melihat

keadaan tersebut, permasalahan dasar yang dihadapi dalam upaya pelestarian cerita rakyat ini adalah kurangnya kesadaran masyarakat akan pentingnya manfaat dari cerita rakyat Bali [1]. Maka dari itu perlu ada pemecahan masalah untuk mengatasi kurangnya kesadaran masyarakat khususnya generasi muda terhadap cerita rakyat. Dengan mengadopsi teknologi yang sedang populer sehingga cerita rakyat diharapkan akan menjadi pedoman hidup terhadap kehidupan generasi muda sehari-hari. Menurut Permana, perkembangan teknologi informasi dan komunikasi saat ini membawa dampak yang sangat besar pada berbagai bidang kehidupan, salah satunya yaitu bidang pendidikan [2].

Salah satu teknologi yang sedang populer saat ini adalah game yang berjalan pada perangkat platform mobile. Permainan (game) juga adalah sarana yang dibuat untuk memenuhi kebutuhan manusia akan hiburan, sehingga sampai saat ini, permainan terus berkembang sesuai dengan kebutuhan dan tidak dapat dipisahkan dari manusia [3]. Game yang bertemakan budaya sangat baik untuk dikembangkan sebagai sarana untuk pendidikan, penyampaian informasi dan sebagai hiburan [4]. Dengan memadukan game dan cerita rakyat akan menjadi salah satu solusi alternatif dan kreatif.
Game merupakan media interaktif yang bersifat menghibur dan cenderung mengasyikkan. Game banyak disukai oleh generasi muda, khususnya game mobile yang banyak diminati dan sedang berkembang saat ini karena dapat digunakan dimana saja dan kapan saja. Game pula memiliki banyak jenis salah satunya adalah game edukasi. Game edukasi adalah permainan yang digunakan dalam proses pembelajaran dan dalam permainan tersebut mengandung unsur mendidik atau nilai-nilai pendidikan. Adapun genre dari game salah satunya adalah game adventure yang menekankan pada jalannya cerita yang diperani oleh pemain. Game juga mempunyai tugas untuk membatasi para perancang game untuk dapat berkreasi dalam ide yang lebih spesifik [5].

Sebelum penelitian ini dilakukan, sudah ada penelitian juga merancang game yang mengangkat cerita rakyat, namun cerita rakyat tersebut mengangkat dari cerita kebudayan Jawa. Adalah game 3D dengan karakter Punakawan sebagai media pengenalan aksara Jawa yang peneliti jadikan contoh. Game ini bercerita tentang seorang Punakawan yang bertualang mengumpulkan ikon-ikon akasara Jawa, namun game ini masih berjalan di Desktop. Pada saat ini game mobile telah banyak diciptakan dan terdapat diberbagai platform. Android, iOS, Windows Phone merupakan beberapa contoh platform yang banyak memiliki game mobile.

Ada pula pengembangan aplikasi yang dilakukan dengan judul Pengembangan Game Banten Berbasis Android mendapatkan hasil dari respon pengguna yang sangat baik berkisar 95,33\% [6]. Hasil itulah yang menjadi acuan untuk dapat ikut berperan serta dalam melestarikan budaya dalam hal ini cerita rakyat.

Dari latar belakang di atas dapat ditarik kesimpulan perangkat mobile sudah memiliki banyak game, tetapi masih sedikit yang mengangkat tema cerita rakyat. Oleh karena itu penulisan termotivasi untuk melakukan "Pengembangan Aplikasi Game Kisah Panji Sakti Berbasis Mobile" yang dimana diharapkan akan meningkatkan 
ketertarikan generasi muda untuk lebih mengenal dan memeahami cerita rakyat daerahnya dan juga memahami pesan yang disampaikan didalam cerita tersebut.

\section{METODE}

Pengembangan game cerita rakyat Panji Sakti ini menggunakan model ADDIE.
Model ADDIE merupakan singkatan dari Analysis, Design, Development, Implementation, dan Evaluation. Model ini dikembangkan oleh Dick and Carry pada tahun 1996. [7]. Berikut Penjabaran penelitian pengembangan game cerita rakyat Panji Sakti sesuai dengan model ADDIE.

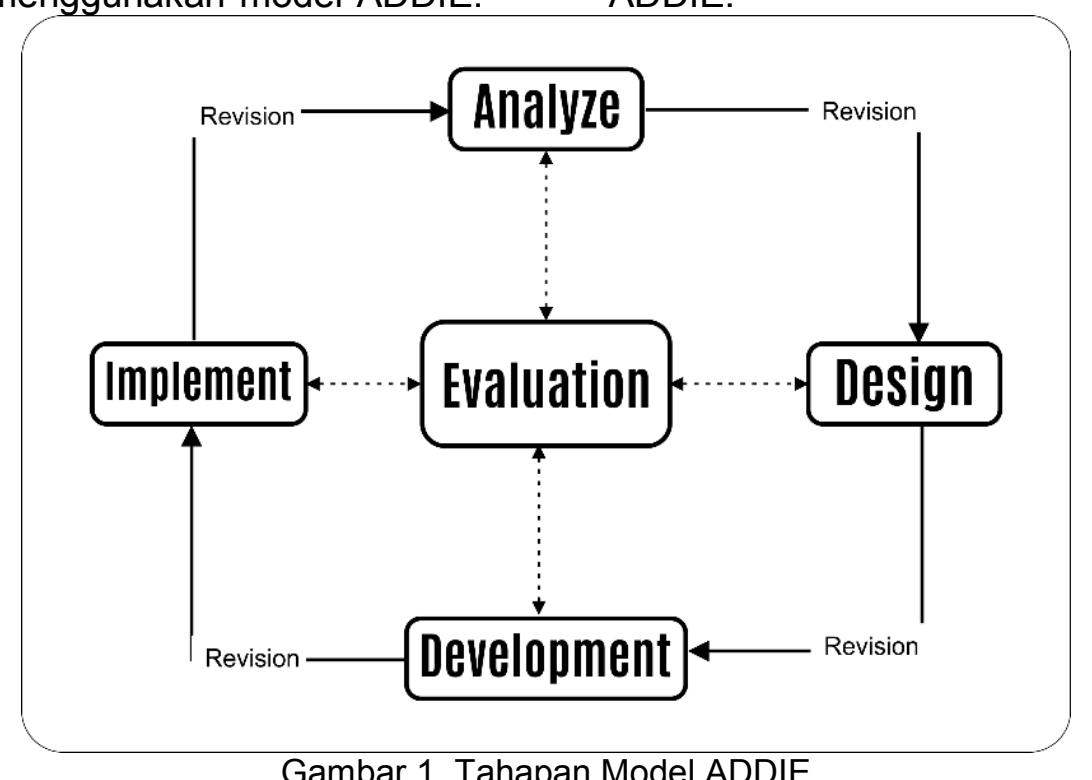

Gambar 1. Tahapan Model ADDIE

\section{A. Analysis (Analisis)}

Pada tahap ini dilakukan analisis kebutuhan fungsional dan non fungsional yang termasuk dalam perencanaan kebutuhan. Perencanaan Kebutuhan (Requirement Planning) merupakan tahap pengumpulan informasi dan kebutuhan secara lengkap kemudian dianalisis dan didefinisikan kebutuhan yang harus dipenuhi. Pada tahap ini peneliti menggali informasi terkait dengan cerita Panji Sakti. Peneliti mencari informasi terkait cerita Panji Sakti dari sumber berupa Babad Bali. Peneliti juga mencari informasi terkait teknologi yang dibutuhkan dalam pengembangan game ini khususnya terkait game engine yang akan digunakan yaitu Unity 3D. Pada tahap ini juga kebutuhan - kebutuhan baik kebutuhan fungsional, kebutuhan non fungsional, kebutuhan perangkat keras, maupun kebutuhan perangkat lunak dianalisis.

\section{1) Kebutuhan Fungsional}

Game cerita rakyat Panji Sakti ini diharapkan dapat memenuhi prosesproses sebagai berikut:
- Mampu memulai permainan baru yang diawali dengan stage 1.

- Mampu menampilkan cerita awal Panji Sakti sebelum stage 1 dimulai.

- Mampu melanjutkan permainan ke stage 2 apabila pengguna telah menyelesaikan stage 1 .

- Mampu melanjutkan permainan ke stage 3 apabila pengguna telah menyelesaikan stage 2 .

- Mampu melanjutkan permainan ke stage 4 apabila pengguna telah menyelesaikan stage 3 .

- Mampu melanjutkan permainan ke stage 5 apabila pengguna telah menyelesaikan stage 4 .

- Mampu melanjutkan permainan ke stage 6 apabila pengguna telah menyelesaikan stage 5

- Mampu melanjutkan permainan ke stage 7 apabila pengguna telah menyelesaikan stage 6

- Mampu melanjutkan permainan ke stage 8 apabila pengguna telah menyelesaikan stage 7 
- Mampu melanjutkan permainan ke stage 9 apabila pengguna telah menyelesaikan stage 8

- Mampu memperlambat dan mengurangi HP (Health Point) karakter yang dimainkan pengguna ketika terkena rintangan dan dihalangi karakter musuh.

- Mampu menampilkan menu Story yang berisikan cerita I Kuluk dan I Kambing yang akan disajikan dalam bentuk gambar dan klip suara.

- Mampu menyimpan permainan.

- Mampu menampilkan menu Credit yang berisikan informasi tentang game dan pengembang.

2) Kebutuhan Non Fungsional

Kebutuhan non fungsional dari game

ini adalah sebagai berikut:

- Game cerita rakyat Panji Sakti ini hanya bisa dijalankan pada perangkat mobile dengan sistem operasi android dan iOS.

- Game cerita rakyat Panji Sakti ini dirancang dengan button yang dapat mempermudah pengguna dalam pengoprasianya.

- Aplikasi harus mampu menampilkan menu utama maksimal 1 menit setelah aplikasi dibuka.

3) Kebutuhan Perangkat Keras
Spesifikasi hardware (perangkat mobile berbasis Android dan iOS) yang digunakan dalam mengembangkan game Cerita Rakyat Panji Sakti ini dengan baik adalah smartphone menngunakan minimal CPU ARM v7 dan RAM 512 MB

\section{4) Kebutuhan Perangkat Lunak}

Spesifikasi yang dibutuhkan untuk mendukung game Cerita Rakyat Panji Sakti adalah smartphone yang memiliki sistem operasi Android dan iOS.

\section{B. Design (Desain)}

Setelah melewati tahap requirement planning, maka tahapan berikutnya adalah tahap perancangan. Berdasarkan model ADDIE, pada tahap perancangan ini peneliti membuat rancangan dari aplikasi dan dilanjutkan dengan pembuatan prototype game. Prototype game selanjutnya akan terus direvisi dan disempurnakan.

\section{1) Use Case Diagram}

Diagram use case adalah sebuah diagram yang digunakan untuk memodelkan dan menyatakan unit fungsi/layanan yang disediakan oleh sistem kepada pengguna. Use case menggambarkan fungsionalitas yang diharapkan dari sebuah sistem. 


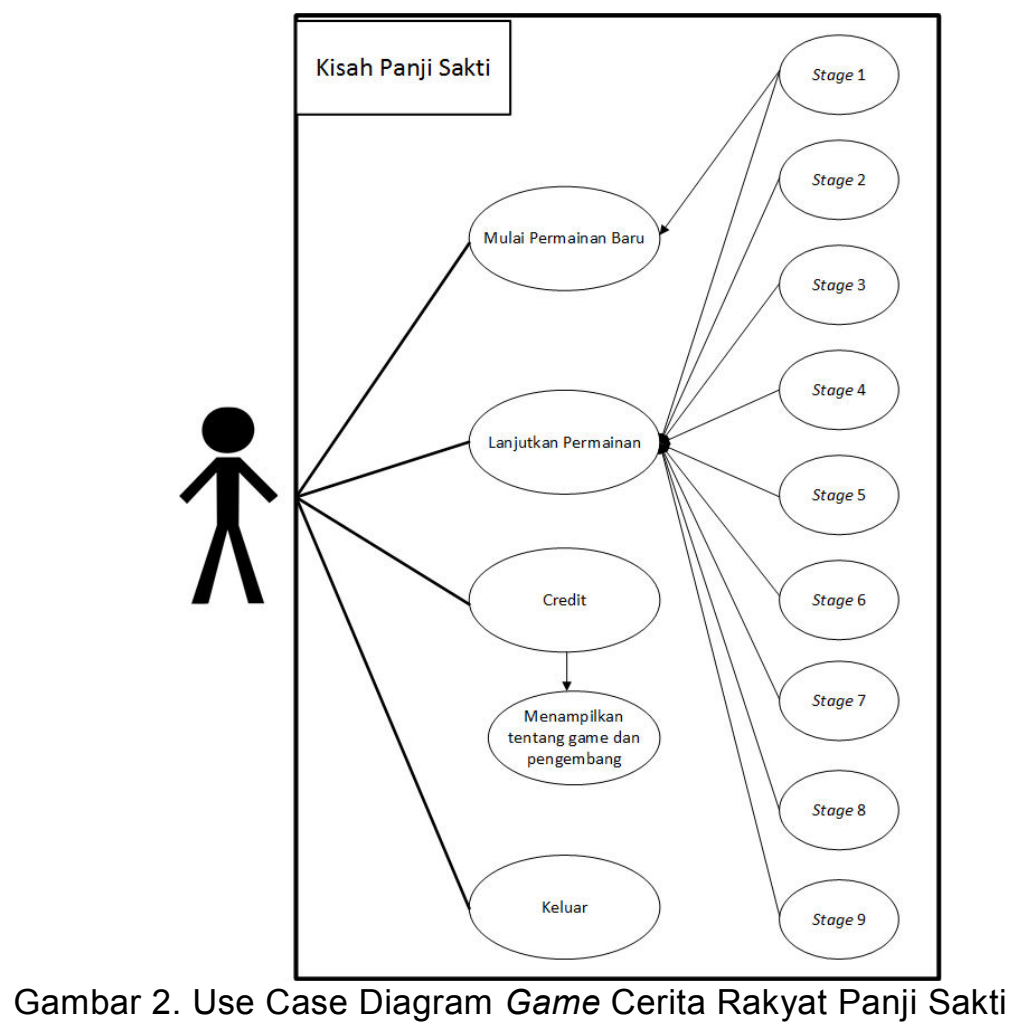

\section{2) Acitivity Diagram}

Activity diagram menggambarkan berbagai alur aktivitas dalam sistem yang sedang dirancang, bagaimana masingmasing alur berawal, decision yang mungkin terjadi, dan bagaimana mereka berakhir. Activity Diagram juga dapat menggambarkan proses paralel yang mungkin terjadi pada beberapa eksekusi. Berikut adalah Activity Diagram yang ada pada Game Kisah Panji Sakti Berbasis Mobile yang meliputi Mulai Permainan Baru (Gambar 3) dan Lanjutkan Permainan (Gambar 4). 


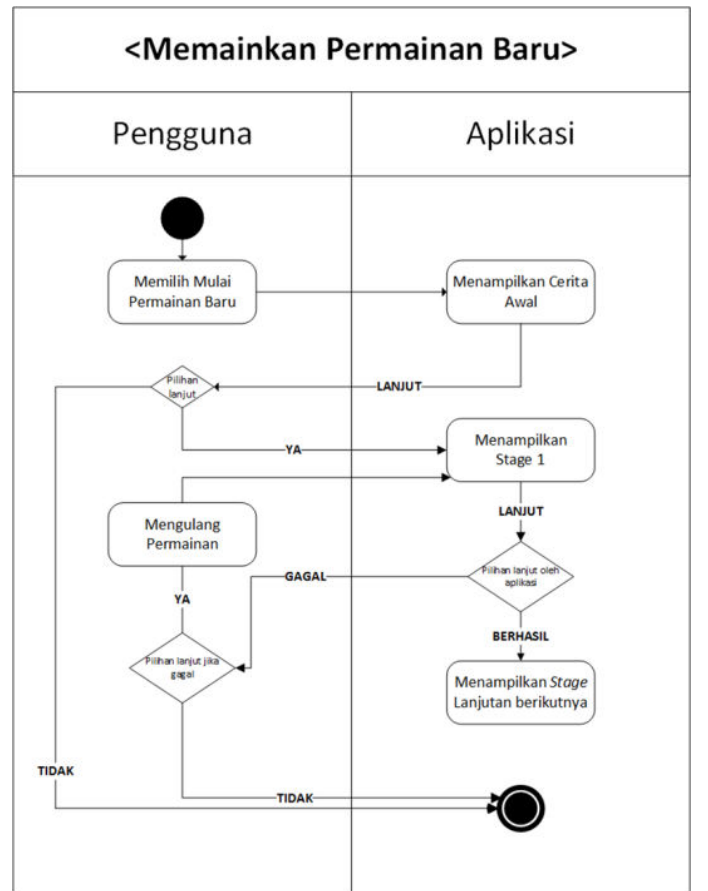

Gambar 3. Activity Diagram Memulai Permainan Baru

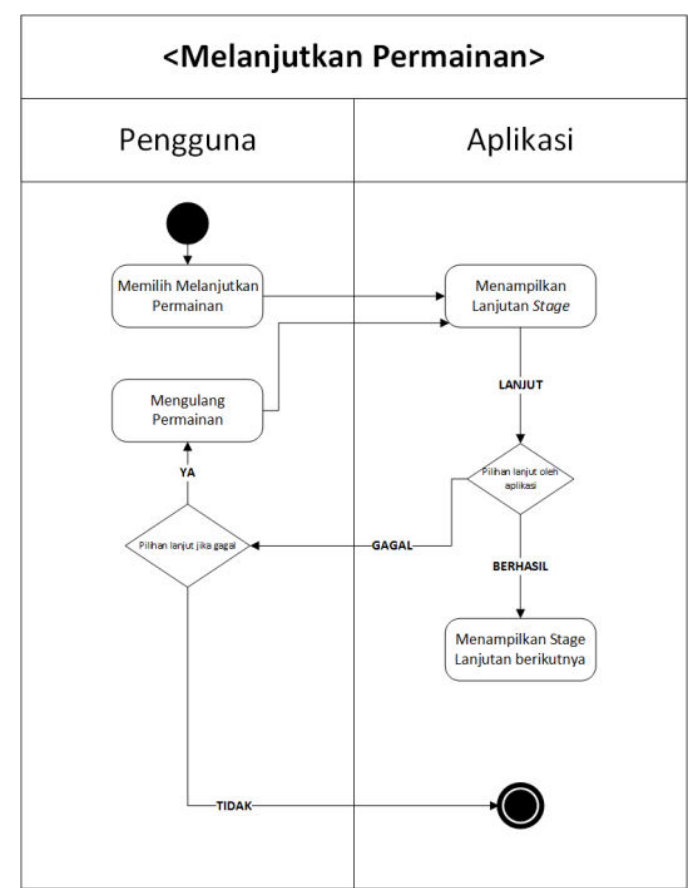

Gambar 4. Activity Diagram Melanjutkan Permainan

\section{Development (Pengembangan)}

Pada tahapan ini dilakukan perancangan source code program yang digunakan dan rancangan antarmuka pada Game Cerita Rakyat "Panji Sakti" Berbasis Mobile.

\section{1) Source Code}

Source Code merupakan pengkodean dari tahap desain kedalam bentuk bahasa pemograman yang membentuk sebuah aplikasi yang utuh dan dapat dijalankan oleh pengguna. Dalam pengembangan Game Cerita Rakyat "Panji Sakti" Berbasis Mobile ini menggunakan bahasa pemograman C\# dimana peneliti menggunakan Unity 3D sebagai game engine untuk membangun game cerita rakyat Panji Sakti ini. Unity 3D 
sebagai game engine berguna untuk membantu peneliti dalam membuat control bagi karakter, menghubungkan setiap scene dalam game, serta membuat sebuah gameplay yang dapat dikendalikan oleh pemain.

\section{Implementation (Implementasi) \\ Tahap selanjutnya adalah} implementasi. Tahap Implementasi atau Implementation ini adalah tahap di mana aplikasi telah siap untuk diperkenalkan dan dilakukan pengujian kelayakan, dalam hal ini aplikasi yang telah dibuat yang adalah Game cerita rakyat Panji Sakti. Pengujian ini dilakukan dengan tujuan untuk memastikan game yang telah dibangun berdasarkan rancangan yang dibuat, sudah benar dan setiap fungsi yang terdapat pada game dapat berjalan dengan baik tanpa adanya error atau kesalahan dalam penggunaannya.

\section{E. Evaluation (Evaluasi)}

Pada tahap ini dilakukan evaluasi pada tahap-ahap diatas. Dengan kata lain pada tahap analysis, design, development, dan implementation dilakukan tahap evaluation. Untuk tahapan analysis, design, development, implementation dilakukan dengan cara konsultasi dan evaluasi oleh dosen pembimbing serta pengisian angket evaluasi. Sedangkan pada tahap akhir dilakukan pembahasan hasil evaluasi dari tahapan tersebut.

\section{HASIL DAN PEMBAHASAN}

\section{A. Hasil}

1) Hasil Tahap Analyze (Analsis)

Tahapan analisis Game Kisah Panji Sakti Berbasis Mobile menggunakan perangkat lunak Sistem Operasi Windows 7, Unity, Corel Draw X5, Photoshop CS5, Sistem Operasi Android, dan Sistem Operasi iOS. Perangkat keras yang digunakan yaitu Acer 4820, Xiaomi Redmi 3, dan iPhone 5.

\section{2) Hasil Tahap Design (Disain)}

Pada tahap evaluasi design ini, didapatkan hasil dari storyboard game yang terdiri dari disain stage dan karakter:

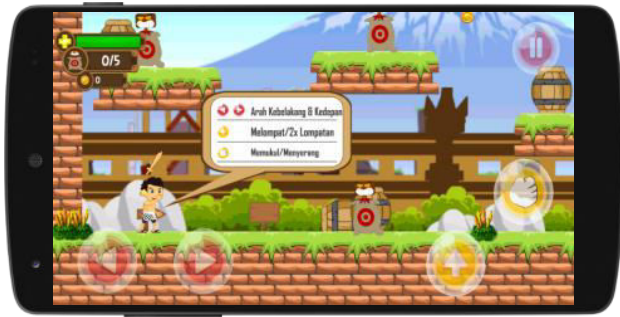

Gambar 5. Stage 1

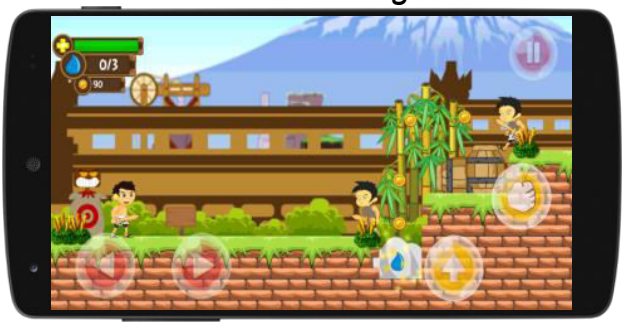

Gambar 6. Stage 2

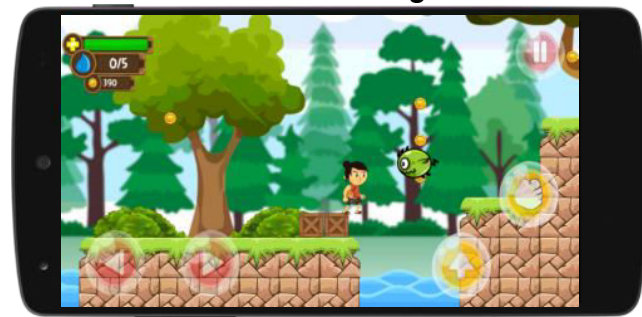

Gambar 7. Stage 3

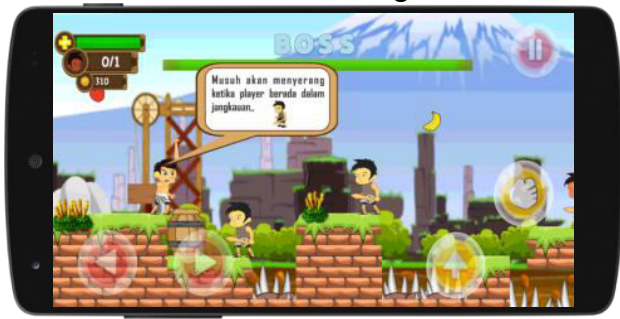

Gambar 8. Stage 4

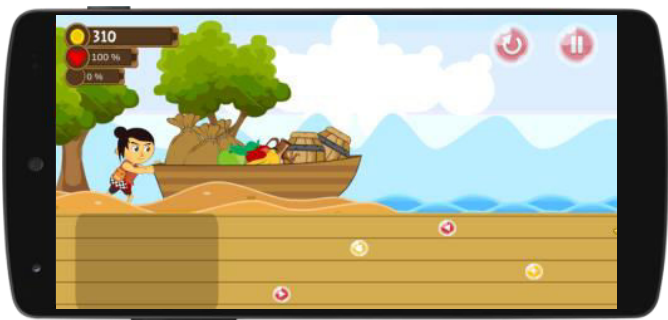

Gambar 9. Stage 5

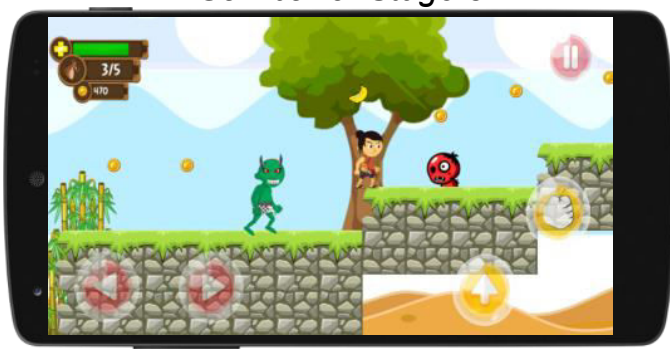

Gambar 10. Stage 6 

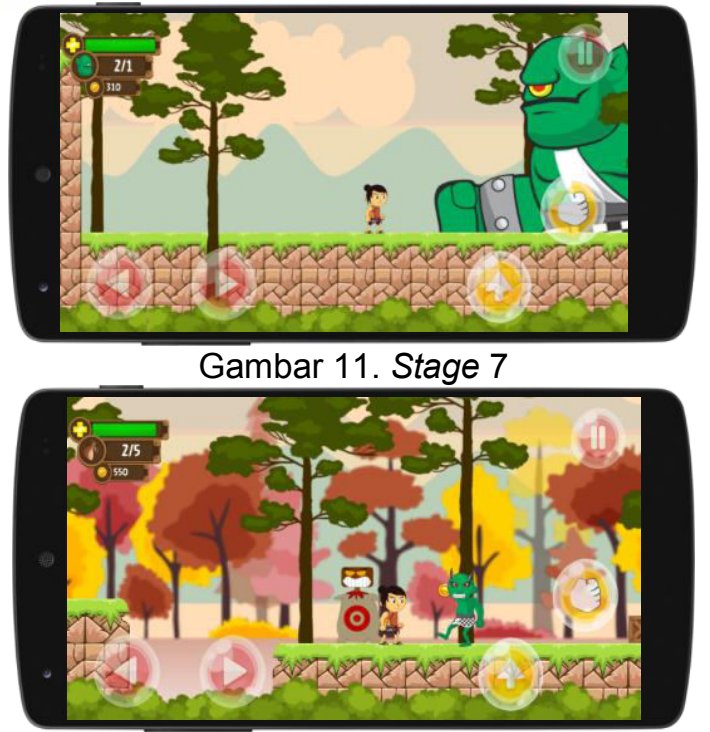

Gambar 12. Stage 8

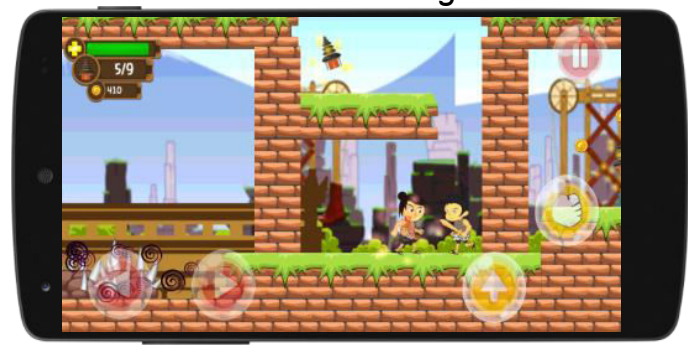

Gambar 13. Stage 9

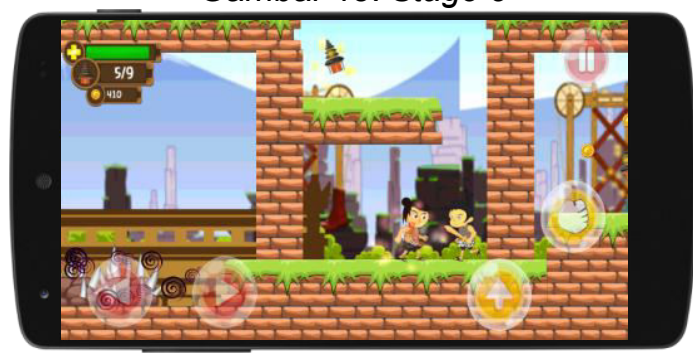

Gambar 14. Stage 9 Gameplay Kedua

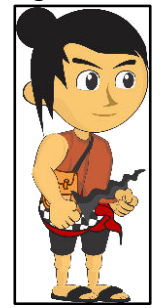

Gambar 15. Panji Sakti Kecil

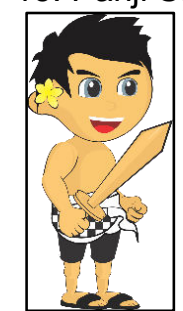

Gambar 16. Panji Sakti Dewasa

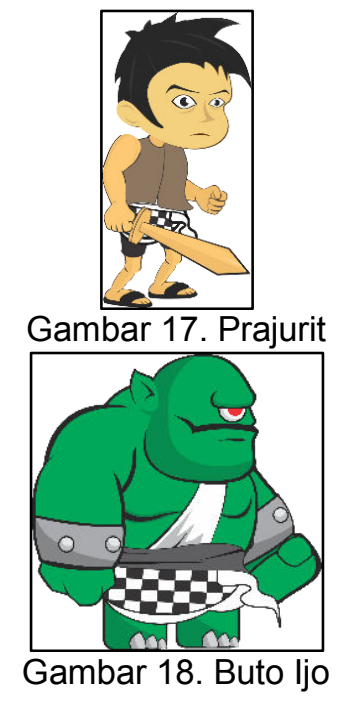

3) Hasil Tahap

(Pengembangan)

Development

Tahapan evaluasi development ini dilakukan dengan melakukan pemograman atau pengkodean dan membuat antarmuka Game Kisah Panji Sakti Berbasis Mobile.

a) Layar Antarmuka Menu Utama

Menu Utama akan muncul setelah Splash. Menu Utama terdiri dari ikon Mulai Baru, Lanjutkan, ikon Keluar, ikon Silent, ikon Tentang Pengembang, dan Ikon Tentang Permainan.

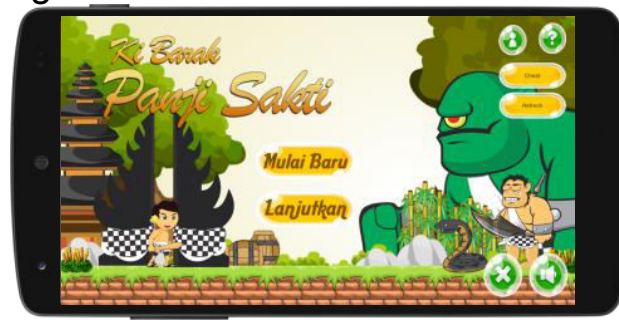

Gambar 19. Layar Antarmuka Menu Utama

b) Layar Antarmuka Lanjutkan

Tampilan Pilihan Stage akan terlihat setelah menekan tombol Lanjutkan. Pada pilihan stage akan terdapat 9 stage yang bisa di pilih, stage akan terkunci jika pemain belum pernah melewati stage sebelumnya.

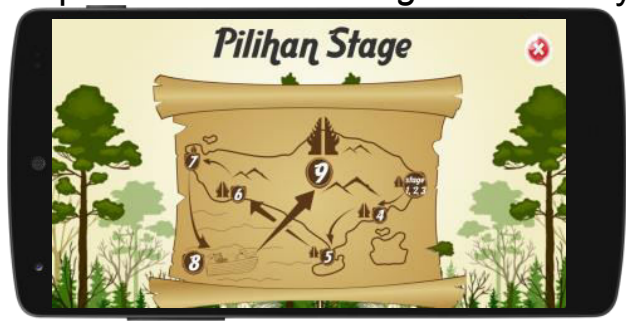

Gambar 20. Layar Antarmuka Lanjutkan

\section{c) Layar Antarmuka Gameplay}


Gameplay akan menampilkan karakter, control, objective, pause, koin, dan health bar.

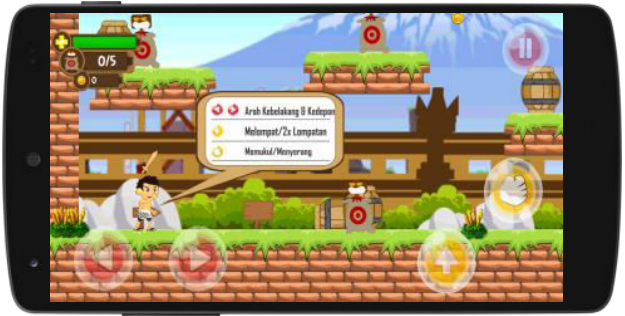

Gambar 21. Layar Antarmuka Gameplay

d) Layar Antarmuka Backstory

Backstory akan menampilkan Kisah

Panji Sakti yang berisikan gambar dan teks.

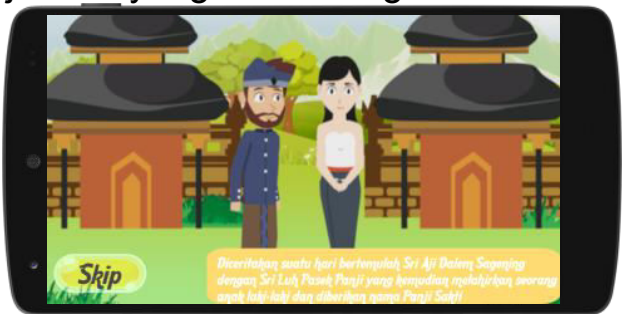

Gambar 22. Layar Antarmuka Backstory

\section{e) Layar Tentang Permainan}

Tentang Permainan akan menampilkan panduan terkait objective, musuh, dan item.

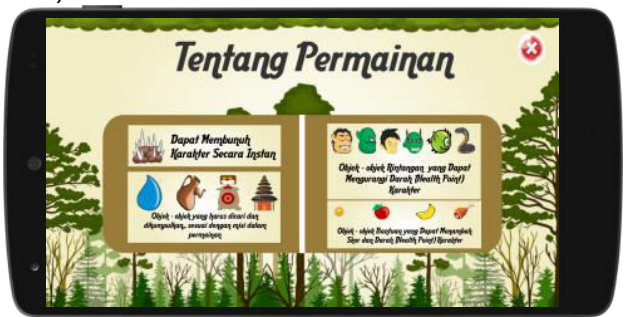

Gambar 23. Layar Tentang Permaian

\section{f)}

Layar Tentang Pengembang

Akan menampilkan informasi terkait identitas pengembang.

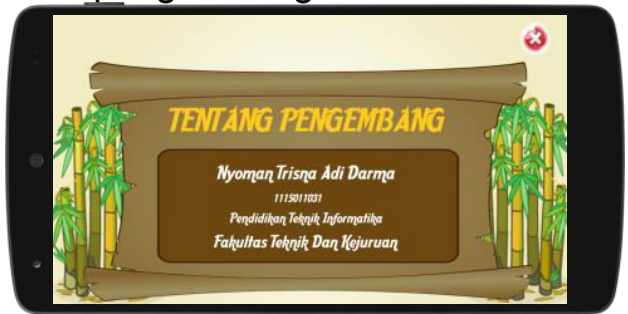

Gambar 24. Layar Tentang Pengembang

g) Layar Splash Screen

Akan menampilkan informasi splash.

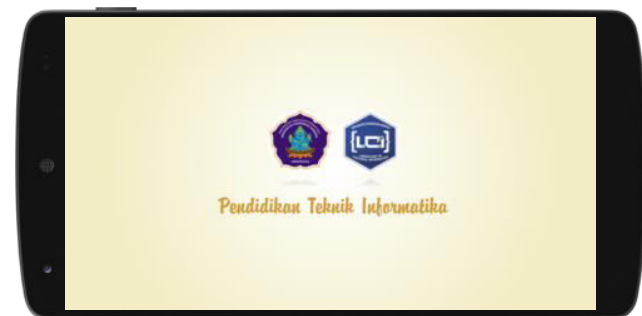

Gambar 25. Layar Splash Screen

4) Hasil (Implementasi)

a) Hasil Uji White Box

Pada uji white box ini dilakukan untuk meramalkan cara kerja perangkat lunak secara rinci, karenanya logical path (jalur logika) perangkat lunak akan dites dengan menyediakan test case yang akan mengerjakan kumpulan kondisi atau pengulangan secara spesifik. Pada tahap uji coba ini, dilakukan oleh pengembang aplikasi Game Kisah Panji Sakti Berbasis Mobile pada Smartphone Android dan iOS dengan hasil secara umum sudah dapat dikatakan sesuai atau tidak terjadi error pada aplikasi. Dari 5 tahapan pengetesan didapatkan hasil sebanyak $100 \%$ berhasil.

\section{b) Hasil Uji Black Box}

Pelaksanaan uji kasus untuk black box testing dilaksanakan beberapa kasus uji sebagai berikut: (1) Pelaksanaan Kasus Uji 1. Pada pengujian kasus uji 1 dilakukan untuk mengetahui apakah game yang dibuat sudah berjalan dengan baik dan benar, dapat digunakan oleh orang lain. Pada tahap uji coba ini dilakukan oleh 2 orang penguji aplikasi yaitu Nyoman Ari Dwismara Putra dan I Wayan Dedy Budiarta dengan diberikan angket setelah menggunakan Game Kisah Panji Sakti Berbasis Mobile. Pada kasus uji 1 yang dilaksanakan pada hari Kamis, 10 Agustus 2017 penggunaan Game Kisah Panji Sakti Berbasis Mobile secara umum sudah dapat dikatakan sesuai dan memuaskan. Dari 17 tahapan pengetesan didapatkan hasil sebanyak $100 \%$ sesuai.

(2) Pelaksanaan Kasus Uji 2. Kasus uji 2 bertujuan untuk mengetahui kebenaran proses Game Kisah Panji Sakti Berbasis Mobile. Kasus uji 2 dilaksanakan pada hari Kamis, 10 Agustus 2017 pada Smartphone 
Android dan iOS oleh penulis, semua proses mulai dari saat pertama kali game dijalankan sampai dengan selesai keluar dari game berfungsi dengan baik. Hasil pengujian kesesuaian proses tersebut, dilakukan oleh pengembang game sendiri, semua fitur pada game berjalan sesuai dengan yang direncanakan sebelumnya.

\section{c) Hasil Uji Ahli Isi}

Pengujian ahli isi dilakukan oleh orang yang benar-benar mengerti akan Cerita Rakyat Bali yaitu oleh Dosen Bahasa Bali di Universitas Pendidikan Ganesha Singaraja dan Dosen Agama Hindu di STKIP Agama Hindu Singaraja sebagai ahli isi yang memahami isi Cerita Panji Sakti. Angket terdiri dari 7 pernyataan yang hasilnya bahwa isi cerita pada Game Kisah Panji Sakti Berbasis Mobile sudah 100\% sesuai.

\section{d) Hasil Uji Ahli Media}

Hasil Uji Media menggunakan aspek usability yang berdasarkan angket yang telah diisi oleh 2 orang ahli media yang merupakan Dosen dan 2 orang mahasiswa. Dalam instrumen pengujian, terdapat 5 katagori yang dinilai. Learnability, Efficiency, Memorability, Error, dan Satisfaction. Untuk presentase hasil uji ahli media Game Kisah Panji Sakti Berbasis Mobile yaitu $91.5 \%$ berarti hasil ujia media dalam rentangan Sangat Baik.

\section{5) Hasil Tahapan Evaluation (Evaluasi) \\ Berdasarkan hasil pengujian yang telah dilakukan maka sudah dapat} ditentukan apakah Game Kisah Panji Berbasis Mobile dikatakan layak atau tidak digunakan. Pada kasus uji 1, penggunaan Game Kisah Panji Berbasis Mobile secara umum sudah dapat dikatakan memuaskan, karena semua smartphone Android dan iOS yang diuji coba sudah mampu menjalankan Game Kisah Panji Berbasis Mobile. Pada kasus uji 2 semua proses mulai dari saat pertama kali game dijalankan sampai dengan selesai keluar dari game berfungsi dengan baik. Semua fitur game dan suara yang ditampilkan sesuai dengan yang diharapkan.
Pada Uji Ahli Isi dan Uji Media dengan aspek usability dilakukan untuk menguji kelayakan produk aplikasi untuk digunakan oleh pengguna. Berdasarkan hasil yang diperoleh dapat disimpulkan bahwa Game Kisah Panji Berbasis Mobile ini, layak digunakan oleh pengguna yang memiliki manfaat sebagai wadah atau media untuk mengenalkan kembali cerita rakyat Bali terutama Panji Sakti agar masyarakat luas dapat mengetahui cerita Panji Sakti.

\section{B. Hasill Repon Pengguna}

Hasil Respon Pengguna dilakukan untuk mengetahui kepuasan memainkan dan tanggapan pengguna tentang Game Kisah Panji Sakti Berbasis Mobile. Uji respon pengguna dilakukan dengan cara menyebarkan angket kepada 30 orang dengan rentangan usia 16 tahun sampai 30 tahun dikalangan pelajar, mahasiswa, dan masyarakat. Sesudah memainkan Game Kisah Panji Sakti Berbasis Mobile. Berdasarkan perhitungan hasil Respon Pengguna Game Kisah Panji Saktu Berbasis Mobile didapatkan persentase sebanyak $85.8 \%$ yang berarti hasil respon dalam rentangan Sangat Baik.

\section{Pembahasan}

Sesuai dengan paparan hasil pengembangan Game Kisah Panji Sakti Berbasis Mobile maka berikut ini diuraikan pembahasan. Pembahasan difokuskan pada implementasi dan hasil respon pengguna serta dilakukan revisi terhadap produk pengembangan aplikasi Game Kisah Panji Sakti Berbasis Mobile.

Berdasarkan hasil pengembangan dapat diketahui bahwa Game Kisah Panji Sakti Berbasis Mobile yang dikembangkan sesuai dengan model ADDIE (Analyze, Design, Development, Implemetation, Evaluation). Tahap analisis (analyze) melakukan implementasi pada spesifikasi perangkat lunak dan perangkat keras. Tahap desain (design) dilakukan pengembangan usecase diagram, activity diagram, scenario game, storyboard game dan design karakter game. Tahap ketiga adalah kegiatan pengembangan (development) meliputi source code game 
dan antarmuka game, dimana pengembangan aplikasi diimplementasikan menggunakan bahasa pemrograman C\# dengan editor Unity. Kegiatan tahap keempat adalah implementasi (implementation) meliputi uji white box, uji black box, uji ahli isi, uji ahli media dengan aspek usebility. Kegiatan terakhir adalah melakukan evaluasi (evaluation) yang meliputi hasil evaluasi dari setiap tahapan model ADDIE.

Berdasarkan hasil pengujian ahli isi yang dilakukan oleh pengembang Game Kisah Panji Sakti Berbasis Mobile dengan angket menunjukan bahwa persentase yang diperoleh adalah $100 \%$ berarti sudah sesuai dengan isi cerita sebenarnya.

Sedangkan berdasarkan persentase hasil uji media dengan aspek usability yang dilakukan untuk menguji kelayakan produk aplikasi yang digunakan oleh pengguna bahwa Game Kisah Panji Sakti Berbasis Mobile ini, layak digunakan oleh pengguna dengan persentase $91.5 \%$ berada pada kualifikasi sangat baik. Adapun masukan setelah melakukan pengujian yaitu pada tombol navigasi serang dan loncat terlalu tipis dan durasi backstory pada setiap stage terlalu cepat. Berdasarkan masukan tersebut, dilakukan revisi terlebih dahulu sebelum digunakan oleh pengguna.

Berdasarkan hasil respon pengguna yang dilakukan dengan cara menyebarkan angket kepada 30 orang dengan rentangan dari usia 16 tahun hingga 30 tahun. Dimana setelah memainkan Game Kisah Panji Sakti Berbasis Mobile dengan hasil angket menunjukkan bahwa persentase yang diperoleh adalah $85.8 \%$ berarti bila dikonversikan ke dalam tabel konversi yang ditunjukkan pada Tabel 3. 3 berada pada kualifikasi sangat baik. Hal ini dinyatakan pada pernyataan angket nomor 3,4 , dan 8 terdapat pernyataan negatif sehingga hasil respon pengguna yang didapat lebih kecil dari pernyataan - pernyataan positif lainnyan. Melihat dari hasil uji respon dan tanggapan dari pengguna, sesuai dengan harapan, game dapat difungsikan sebagai media untuk menyampaikan kekayaan Budaya Indonesia kepada generasi yang lebih muda [8], sejalan dengan Wati S., menyampaikan game dapat dimanfaatkan oleh masyarakat dan kaum pendidik sebagai media untuk menyampaikan berbagai jenis pendidikan dan pembelajaran tentang budaya yang menarik dan menyenangkan [9]. Namun perlu diperhatikan, menurut Oktaviani dianjurkan bagi semua kalangan baik anak-anak maupun pelajar agar jangan terlalu sering untuk memainkan game, agar tidak menimbulkan dampak negative dari game [10].

Adapun tanggapan dari pengguna yaitu aplikasi game menarik, sederhana dan sangat mudah dimainkan, sangat baik untuk melestarikan cerita rakyat Bali khususnya cerita Panji Sakti, game disarankan dibuat dengan Bahasa Inggris.

\section{SIMPULAN}

Berdasarkan penelitian aplikasi "Pengembangan Game Kisah Panji Sakti Berbasis Mobile" yang telah dilakukan, maka diperoleh kesimpulan sebagai berikut: (1) Perancangan Game Kisah Panji Sakti Berbasis Mobile telah berhasil dirancang dengan menggunakan model fungsional berupa UML (Unified Modeling Language) yaitu dengan menggunakan use case diagram dan activity diagram. (2) Game Kisah Panji Sakti Berbasis Mobile telah berhasil diimplementasikan sesuai dengan rancangan yang telah dibuat sebelumnya. Game Kisah Panji Sakti Berbasis Mobile diimplementasikan menggunakan bahasa pemrograman C\# dengan editor Unity. (3) Hasil pengujian yang sudah dilakukan, masuk dalam rentangan Sangat Baik dilihat dari hasil pengujian uji ahli isi dengan presentase $100 \%$ yang berarti sudah sesuai dengan isi cerita Panji Sakti dan uji ahli media dengan aspek Usability yaitu $87 \%$ berarti hasil respon dalam rentangan Sangat Baik. (4) Hasil respon pengguna Game Kisah Panji Sakti Berbasis Mobile didapatkan persentase sebanyak $86 \%$ yang berarti hasil respon dalam rentangan Sangat Baik.

Berdasarkan simpulan yang disampaikan terdapat beberapa saran untuk pengembangan aplikasi selanjutnya, yaitu (1) Pengembang selanjutnya bisa membuat game dengan tambahan Bahasa Inggris. (2) Pengembang selanjutnya bisa 
melanjutkan mebuat game dengan melanjutkan cerita Panji Sakti yang memimpin Desa Den Bukit sampai beliau tutup usia. (3) Pengembang selanjutnya bisa menambahkan item - item supaya game lebih menarik. (4) Pengembang selanjutnya bisa membuat animasi cerita yang lebih menarik pada game saat ini. (5) Pengembang selanjutnya dapat nyuguhkan gameplay yang lebih menarik sehingga pengguna tidak bosan dalam memainkan game.

Beberapa saran yang ada diharapkan pada pengembangan aplikasi berikutnya dapat membuat game yang lebih baik dan dapat pula meningkatkan pemahaman masyarakat terhadap cerita rakyat setempat. Dengan masyarakat diharapkan dapat menceritkan cerita rakyat kepada generasi penurus agar cerita rakyat terus dapat didengar dan dihayati nilai - nilai moral yang ada di dalamnya.

\section{REFERENSI}

[1] Pratiwi, A. R., 2013. Perancangan Game Puzzle Cupak Gerantang dan Media Pendukungnya Sebagai Upaya Meningkatkan Pelestarian Cerita Rakyat Bali. -, -(-), p. 7.

[2] Permana, P. T. H., Darmawiguna, I G. M., Kesiman, M. W. A., 2014. JA-KO Balinese Pizza: Game Edukasi Interaktif Jaringan Komputer. Jurnal Nasional Pendidikan Teknik Informatika (JANAPATI), III(2).

[3] Ekasari, Y., 2012. Merancang Game Petualangan Binggo Menggunakan Unity 3D Game Engine, Yogyakarta: STIKOM AMIKOM.

[4] Utomo, P. R. \& Lakoro, R., 2012. Perancangan Concept Art Game Berlatar Budaya Majapahit Sebagai Media Komunikasi Budaya. JURNAL TEKNIK POMITS, I (1), pp. 1-5.

[5] Tjahyadi, M. P., Sinsuw, A., Tulenan, V. \& Sentinuwo, S., 2014. Prototipe Game Musik Bambu Menggunakan Engine Unity 3D. E-journal Teknik Informatika, IV(2), pp. 1-6.

[6] Wicaksana, I G. A., Arthana, I K. R., Wirawan, I M. A., 2017. Pengembangan Game Banten Berbasis Android. Kumpulan Artikel
Mahasiswa Pendidikan Teknik Informatika, VI(1), pp. 1-8.

[7] Mulyatiningsih, E., 2012. Metode Penelitian Terapan Bidang

Pendidikan. Bandung: CV. Alfabet.

[8] Utomo, P. R. \& Lakoro, R., 2012. Perancangan Concept Art Game Berlatar Budaya Majapahit Sebagai Media Komunikasi Budaya, JURNAL TEKNIK POMITS, I(1), pp. 1-5.

[9] Wati, M. S., Darmawiguna, I G. M., Putrama, I M., 2016. Pengembangan Game "Menoboros Kidang" Sebagai Bentuk Pelestarian Tradisi Meboros di Bali. Kumpulan Artikel Mahasiswa Pendidikan Teknik Informatika (KARMAPATI), V(1). pp. 1-8.

[10] Oktaviani, N., Saputri, N. A. O., 2015. Perancangan Mini Game Bergenre Adventure Menggunakan Aplikasi Game Maker. Jurnal Nasional Pendidikan Teknik Informatika (JANAPATI), IV(3). 